\title{
Gale crater: the Mars Science Laboratoryl Curiosity Rover Landing Site
}

\author{
James J. Wray \\ School of Earth and Atmospheric Sciences, Georgia Institute of Technology, 311 Ferst Drive, Atlanta, GA 30332-0340, USA \\ e-mail: jwray@gatech.edu
}

\begin{abstract}
Gale crater formed from an impact on Mars 3.6 billion years ago. It hosts a central mound nearly $100 \mathrm{~km}$ wide and $\sim 5 \mathrm{~km}$ high, consisting of layered rocks with a variety of textures and spectral properties. The oldest exposed layers contain variably hydrated sulphates and smectite clay minerals, implying an aqueous origin, whereas the younger layers higher on the mound are covered by mantle of dust. Fluvial channels carved into the crater walls and the lower mound indicate that surface liquids were present during and after deposition of the mound material. Numerous hypotheses have been advocated for the origin of some or all minerals and layers in the mound, ranging from deep lakes to playas to mostly dry dune fields to airfall dust or ash subjected to only minor alteration driven by snowmelt. The complexity of the mound suggests that multiple depositional and diagenetic processes are represented in the materials exposed today. Beginning in August 2012, the Mars Science Laboratory rover Curiosity will explore Gale crater by ascending the mound's northwestern flank, providing unprecedented new detail on the evolution of environmental conditions and habitability over many millions of years during which the mound strata accumulated.
\end{abstract}

Received 30 June 2012, accepted 27 July 2012, first published online 24 September 2012

Key words: Mars, Gale crater, Curiosity rover, Mars Science Laboratory, Mount Sharp, remote sensing, geomorphology, stratigraphy, infrared spectroscopy.

\section{Introduction}

Gale is a Martian impact crater $\sim 154 \mathrm{~km}$ in diameter $(D)$, centred near $5^{\circ} \mathrm{S}, 138^{\circ} \mathrm{E}$. It has an interior mound composed of layered rocks up to $\sim 5 \mathrm{~km}$ high, formally named Aeolis Mons (informally Mount Sharp), which may represent the thickest exposed stratigraphic reference section for environmental change on Mars (Grotzinger \& Milliken 2012). The hypothesis that some of these layered rocks formed in a lake (e.g. Cabrol et al. 1999) has made Gale a site of great geological and astrobiological interest. It was proposed as a candidate landing site for the Mars Exploration Rover (MER) mission (Bridges 2001), but was eliminated because the MER landing position uncertainty ellipse was wider than any flat portions of the crater floor (Golombek et al. 2003).

The Mars Science Laboratory mission uses a guided entry approach to give its rover, Curiosity, a much smaller landing ellipse than the MERs Spirit and Opportunity. The mission's primary objective is to explore a site on Mars and quantitatively assess its habitability, and the site selection process reflected this focus (Grant et al. 2011; Golombek et al. 2012). Particular emphasis was placed on mineralogic and morphologic evidence for liquid water, which is the component of habitability most readily assessed using orbital data. Gale hosts multiple hydrated minerals (phyllosilicates and sulphates) in some layers of Mt. Sharp (Milliken et al. 2010), while dozens of channels, inverted channels and fan-shaped deposits attest to past flow of water (Anderson \& Bell 2010; Thomson et al. 2011). The opportunity to study several distinct aqueous environments in a relatively well-preserved stratigraphic sequence led to Gale's selection as the landing site for Curiosity.

For the most part, each prior study of Gale has emphasized a specific type of data (e.g. thermophysical properties, nearinfrared (IR) spectroscopy, or textures in high-resolution images) and/or a specific feature of the crater (e.g. its sand dunes or its possible lacustrine history). Here, I incorporate findings from all of these studies into a comprehensive overview of the crater's geologic history and astrobiological potential prior to Curiosity's investigations there. First, the regional context, the nature of pre-existing materials and timing constraints on Gale's formation are discussed. The next section provides a detailed description of Mt. Sharp strata, followed by discussion of their modification by surficial and subsurface liquid water. The subsequent section presents many hypotheses that have been advanced for the formation of Mt. Sharp and evaluates them in the context of observations discussed previously. The paper concludes with a consideration of the habitability and preservation potential of environments in Gale, followed by brief comments on potential future studies of Gale.

\section{Regional context}

Gale lies in the northwestern portion of the Aeolis quadrangle (Fig. 1). It formed on terrain sloping down from the Noachian southern highlands to the Hesperian lowlands, which likely 


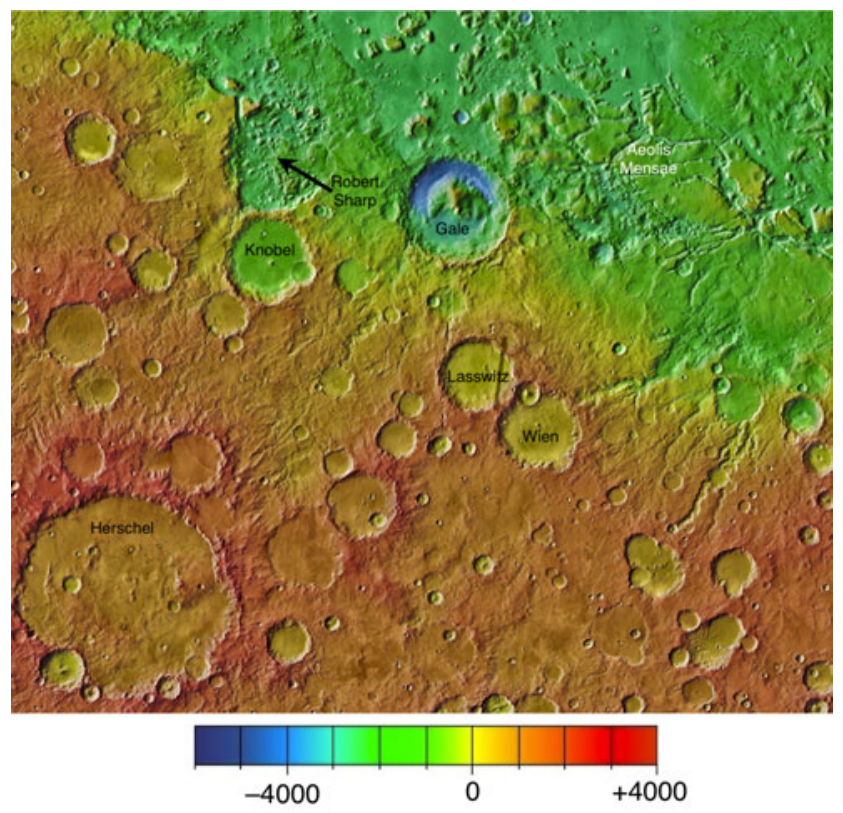

Fig 1. THermal EMission Imaging System (THEMIS) Daytime IR mosaic colourized with MOLA elevations, with Gale and neighbouring large craters labelled. Elevations range from $-4670 \mathrm{~m}$ on Gale's northwestern floor to +3440 m on Herschel's northwestern rim. Gale's diameter is $154 \mathrm{~km}$ for scale. North is up in this and subsequent figures unless otherwise indicated.

accounts at least partly for its northern floor (recently named Aeolis Palus) and rim being $\sim 1-2 \mathrm{~km}$ lower in elevation than its southern floor and rim. The northern floor reaches a minimum elevation of $-4670 \mathrm{~m}$ relative to the Mars Orbiter Laser Altimeter (MOLA) areoid; Tombaugh crater $\sim 1500 \mathrm{~km}$ to the east/northeast is the nearest location that reaches a lower elevation, and the only deeper locations in the entire southern hemisphere occur in Hellas and Argyre basins and in the Valles Marineris and surrounding chaos regions. Gale's depth is an advantage for landing there and has implications for the hydrology, as discussed in a subsequent section.

Similarly sized craters adjacent to Gale, such as Lasswitz and Wien to the south and Knobel to the west, appear substantially more degraded (Fig. 1), with flat floors, buried (Lasswitz) or nearly buried (Wien, Knobel) central uplifts, subtle rims and no well-preserved ejecta (Greeley \& Guest 1987). Such features are characteristic of craters formed and modified under the high-erosion rates of the Noachian Period (Chapman \& Jones 1977; Tanaka 1986; Strom et al. 1992; Craddock \& Maxwell 1993; Craddock \& Howard 2002), so these craters likely predate Gale, as also implied by the superposition of small crater chains extending radially from Gale (probably its secondary craters) across the filled floor of Lasswitz and the rim of Wien crater. The newly named Robert Sharp crater west of Gale has an interior spanned by $>$ km-high mesas and troughs; this fretted or knobby terrain is characteristic of the highlands-lowlands dichotomy boundary all across Mars, but such terrain likely developed in the early Hesperian $(\sim 3.7-3.5 \mathrm{Ga})$, whereas the dichotomy itself dates to the early or pre-Noachian $>4 \mathrm{Ga}$ (Irwin \& Watters 2010). Unlike

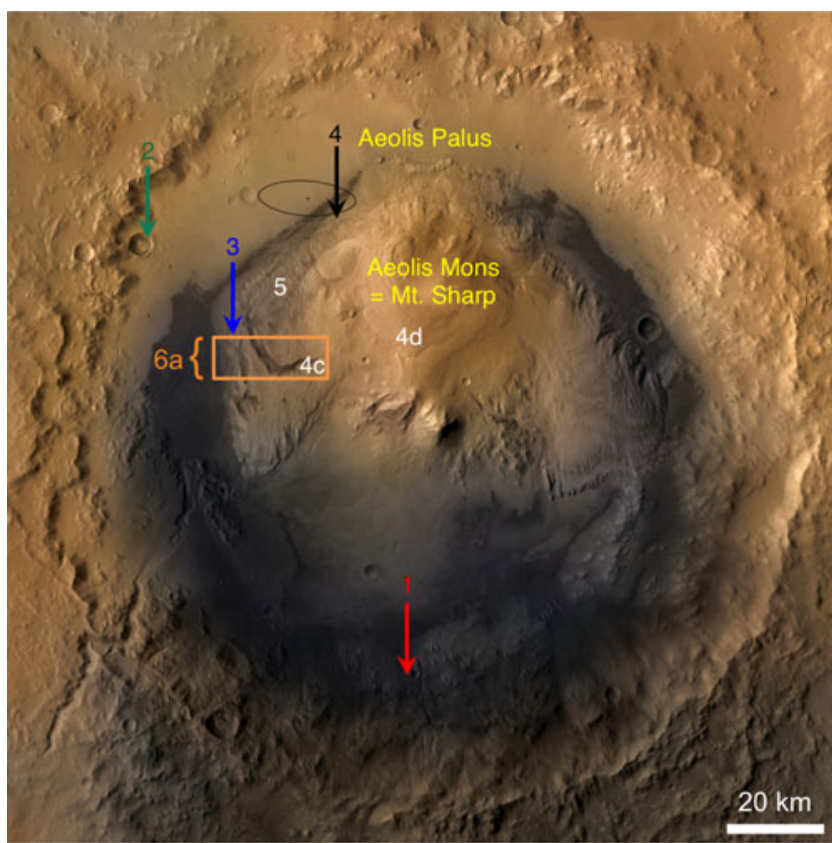

Fig. 2. Gale crater image mosaic. Small black cross on northwest crater floor is Curiosity's target landing site, with a 99\% probability of landing within the black ellipse. Arrows point to locations of Fig. 3 spectra; other numbers indicate locations of subsequent figures (box outlines Fig. 6a). Produced from a combination of High-Resolution Stereo Camera, Context Camera and Viking Orbiter data (from http:// www.nasa.gov/mission_pages/msl/multimedia/pia15687.html). Landing ellipse is $\sim 20 \mathrm{~km}$ wide and $7 \mathrm{~km}$ high.

Robert Sharp crater, Gale contains no fretted or knobby terrain and retains its northern rim, again implying a relatively young age, although Gale's ejecta distribution has led some authors to infer it formed prior to development of the fretted terrain immediately to its east/northeast, Aeolis Mensae (Irwin et al. 2004, 2005).

Dark sand is present on many crater floors in this region. Active sand ripple migration has been observed in Herschel basin (Bridges et al. 2012a) and recently in Gale itself, in the dune field just south of Aeolis Palus (Silvestro et al. 2012). An approximately $15 \times 30 \mathrm{~km}$ sand sheet spans most of Gale's western floor, and dark sand dunes are present in many other areas of the topographic 'moat' surrounding Mt. Sharp (Fig. 2). Very coarse sands (grain size $>1 \mathrm{~mm}$ ) appear dominant (Pelkey \& Jakosky 2002), although some dunes on the southern crater floor have thermal inertia consistent with medium sand (Hobbs et al. 2010), comparable to the dark 'El Dorado' sands observed by Spirit in Gusev crater (Sullivan et al. 2008). The intracrater sands may be related to a dark zone that extends southward from Gale into Lasswitz crater, which could be a wind streak developed by northerly winds blowing sand up the southern crater wall and over the rim, similar to crater wind streaks in Meridiani Planum (Geissler et al. 2008), or could be an external source for the sand within Gale (Pelkey \& Jakosky 2002); however, an apparent enrichment in low-Ca pyroxene in the dark streak relative to materials inside Gale (Anderson \& Bell 2010) may preclude a simple relationship 


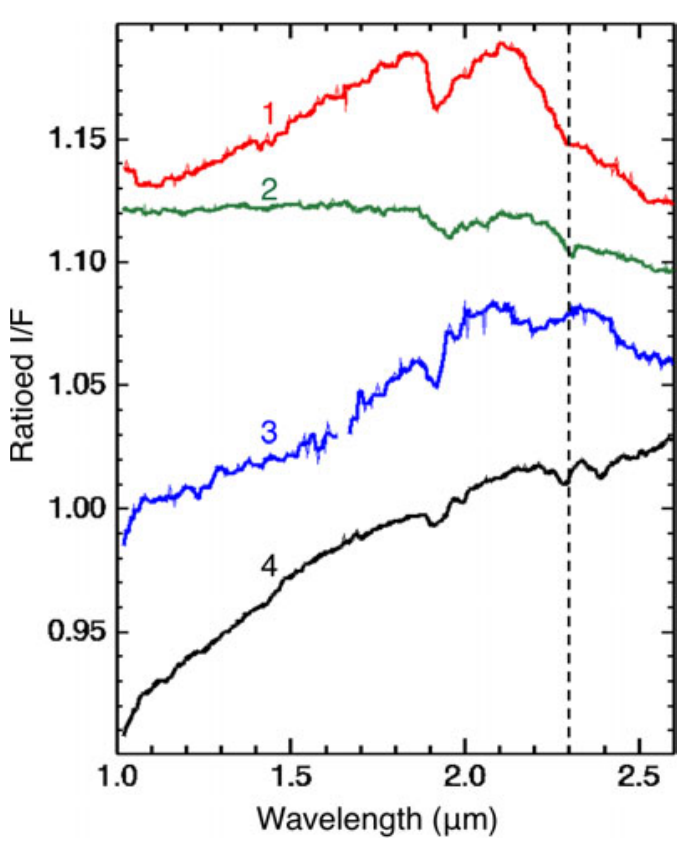

Fig. 3. CRISM ratio spectra (area of interest divided by nearby spectrally neutral area in the same scene) of various hydrous phases in Gale crater, vertically offset for clarity. Spectrum 1 (60 pixels divided by 132 pixels) has a drop-off and inflection at $2.3 \mu \mathrm{m}$, possibly consistent with mixed-layer Fe/Mg-smectite + chlorite (CRISM FRT0000B5A3). Spectrum 2 (117/135 pixels) has a minimum at $2.31 \mu \mathrm{m}$ consistent with Mg-smectite (FRT0001791F). Spectrum 3 (426/486 pixels) has a broad $\sim 2.2 \mu \mathrm{m}$ absorption that may be consistent with hydrated silica and/or gypsum mixed with other hydrated sulphates in the Lower formation (FRT00017327). Spectrum 4 is a typical $\mathrm{Fe}(+\mathrm{Al})$-smectite from the Lower formation, with an absorption at $2.29 \mu \mathrm{m}$ (FRT0000C518; compare with Fig. 3b of Milliken et al. 2010).

between them. Hobbs et al. (2010) found no apparent sand sources in the crater walls, but a global study by Tirsch et al. (2011) suggests that dark sand is usually sourced from exhumed rock layers within each host crater, and some dark 'marker beds' within Mt. Sharp (Milliken et al. 2010) could be local sand sources. Thermal IR spectra imply a sand composition consistent with olivine basalt: $\sim 30 \%$ pyroxene, $\sim 15 \%$ olivine, $\sim 20 \%$ each of feldspars and unknown highsilica phases and 15\% other minerals (Rogers \& Bandfield 2009). Tirsch et al. (2011) found generally similar mafic compositions for dark intracrater sands globally, with high-Ca pyroxene dominating over low-Ca pyroxene based on near-IR spectroscopy. Both thermal and near-IR datasets imply higher olivine abundances in these sands than in most plausible basaltic source rocks on Mars, with olivine enrichment possibly due to Aeolian grain sorting (Sullivan et al. 2008; Mangold et al. 2011).

Gale sits on the edge of a high-dust cover region of the northern plains (Ruff \& Christensen 2002). Mt. Sharp has a bright, low-thermal inertia coating interpreted as dust cover that increases with elevation on the mound, exceeding a few centimetres in thickness (and possibly substantially thicker) near the summit (Pelkey \& Jakosky 2002). A similar trend of increasing dust cover with elevation is observed on the crater walls (Pelkey et al. 2004).

Just a few crater diameters to the north and east of Gale lies the westernmost outcrops of the Medusae Fossae Formation (MFF) mapped by Greeley \& Guest (1987). This extensive, kilometres-thick formation of friable, massive to finely layered, low-density (Carter et al. 2009) deposits has been most commonly interpreted as pyroclastic ash-flow or ash-fall tuff (e.g. Scott \& Tanaka 1982; Bradley et al. 2002; Mandt et al. 2008), possibly from Tharsis or Elysium volcanic sources or from the centrally located Apollinaris Patera (Kerber et al. 2011). Some Aeolian reworking of this material prior to deposition is likely, as observed in the Home Plate pyroclastic deposit in Gusev crater (Lewis et al. 2008a), and widespread sinuous ridges in the lower member of the MFF indicate persistent fluvial erosion and deposition also occurred (Burr et al. 2009). An Amazonian age was originally inferred for the MFF based on crater counts (Scott \& Tanaka 1982; Greeley \& Guest 1987; Tanaka 2000; Bradley et al. 2002; Werner 2009), but more recent work demonstrates that much of the formation was in fact emplaced during the Hesperian (Kerber \& Head 2010; Zimbelman \& Scheidt 2012), consistent with stratigraphic inferences by Schultz \& Lutz (1988). Updated maps reveal MFF outliers just $\sim 20 \mathrm{~km}$ northeast of Gale's rim (Zimbelman \& Scheidt 2012), and the upper strata of Mt. Sharp within Gale may correlate to the MFF (e.g. Thomson et al. 2008, 2011), specifically its middle (Scott \& Chapman 1995) and/or lower member (Zimbelman \& Scheidt 2012).

\section{Gale crater formation and excavation of older materials}

Estimates of Gale crater's age have ranged from late Noachian (Cabrol et al. 1999) to Amazonian (Zimbelman 2010). Gale was mapped as a Hesperian or Amazonian crater by Scott \& Chapman (1995). More recent crater counts on Gale's ejecta using higher-resolution imagery give a tightly constrained age estimate of $\sim 3.6 \pm 0.05 \mathrm{Ga}$, corresponding to the early Hesperian or possibly the late Noachian Epoch (Le Deit et al. 2012). Similar work by Thomson et al. (2011) gives a consistent age near the Noachian-Hesperian boundary. Although crater counts on Mt. Sharp itself imply a late Hesperian/early Amazonian age, significant erosion and burial/exhumation of these craters is evident, especially in the lower mound, implying that this age merely indicates the mean exposure time of the mound's present surface. A more heavily cratered unit on Gale's floor that onlaps (and therefore postdates) the lower mound strata is early Hesperian in age (Thomson et al. 2011), so Gale must have formed and begun accumulating material by the early Hesperian.

The plains just beyond Gale's ejecta to the south are Noachian in age (Greeley \& Guest 1987; Scott \& Chapman 1995), suggesting that rocks from these pre-existing Noachian terrains may be exposed in the crater's southern rim. Some of this Noachian material may have been transported into Gale 
via mass wasting and fluvial erosion of its rim and wall rocks. Gale's northernmost rim segment rises from less cratered, less dissected downslope terrain on the northern margin of the preexisting dichotomy boundary, so its uppermost strata (and any deposits on the northern crater floor sourced from them) may be late Noachian/early Hesperian materials from the margin of the northern plains.

The highest point in Gale's interior, reaching $838 \mathrm{~m}$ above the MOLA areoid, has been mapped as a preserved central uplift formed by the impact process (Scott \& Chapman 1995; Cabrol et al. 1999; Le Deit et al. 2011b). Unlike the rest of Mt. Sharp, this summit area shows no evidence for internal stratification, terracing or wind etching; its knobby appearance is more similar to the crater rim and surrounding plains (Anderson \& Bell 2010). Dust cover obscures the composition of this material as viewed from orbit (Pelkey et al. 2004). It is nearly $\sim 10$ times the typical height of central peaks in craters of Gale's size (Garvin et al. 2003), even exceeding the height of the crater rim after correcting for the regional slope along the dichotomy boundary (e.g. Le Deit et al. 2011b). Possible explanations include a complex pre-impact topography and/or erosional lowering of the crater rim relative to the central uplift, as the latter may have been protected by prior burial beneath Mt. Sharp strata.

Most materials in Gale that predate the crater are dustcovered, but some superposed fresh impact craters provide insights into the composition of these materials (Fig. 2). A $D \sim 1.8 \mathrm{~km}$ bowl-shaped crater on Gale's southern wall appears to have ejected material with a spectral signature of $\mathrm{Fe} / \mathrm{Mg}$-rich phyllosilicates, but with an asymmetric $2.3 \mu \mathrm{m}$ absorption (Fig. 3) that appears more reminiscent of mixedlayer chlorite/smectite clays than of the unaltered smectites found in Mt. Sharp (Milliken et al. 2011). Such mixed-layer clays may be the most common phyllosilicates in the Martian highlands (Milliken et al. 2011), reflecting diagenesis of preexisting smectites (e.g. Tosca \& Knoll 2009) prior to Gale's formation. Similarly, a $D \sim 4.5 \mathrm{~km}$ impact crater on the northwestern corner of Gale's floor (Fig. 2) exposes Mgsmectite in its upper walls, distinct from the $\mathrm{Fe}(+\mathrm{Al})$-smectite found in lower Mt. Sharp strata (Fig. 3). This clay-bearing material is likely excavated from Gale crater fill rather than pre-existing bedrock, but given its location at the base of Gale's northwest wall, this fill may be composed of material eroded from Gale's rim. Alternatively, the $D \sim 4.5 \mathrm{~km}$ crater may expose hydrothermally altered material from a fracture zone developed shortly after the impact that formed Gale (Schwenzer et al. 2012).

\section{Mound composition and textures}

Cabrol et al. (1999) first noted layering in the upper portion of Mt. Sharp and apparent terracing in the lower mound, which more recent imagery reveals to be layered as well (e.g. Edgett and Malin 2001; Anderson \& Bell 2010). Some of the apparent terraces are non-horizontal and likely due to differential wind erosion of strata with varying physical properties (Thomson et al. 2011), although others approximately follow elevation contours so an origin via wave-cut erosion cannot be ruled out (Le Deit et al. 2011b). Regardless, Mt. Sharp may contain as much as $\sim 1.7 \times 10^{4} \mathrm{~km}^{3}$ total volume of layered deposits (Thomson et al. 2011), although (as noted by Cabrol et al. 1999) Gale is large enough to have originally formed a central peak ring rather than an isolated peak (Schwenzer et al. 2012), so if its sedimentary deposits are draped over a large central uplift structure then their overall volume may be less.

Metre-scale imagery reveals a rich diversity of physical properties such as tone and texture that can be used to distinguish units deposited sequentially to form Mt. Sharp, some of which were eroded or impacted prior to deposition of the subsequent layer (Malin \& Edgett 2000; Edgett \& Malin 2001). Such unconformities in the stratigraphic record indicate that deposition spanned a significant period of time, with hiatuses interspersed. Edgett \& Malin (2001) noted that units deposited prior to the most notable unconformity (their stratigraphic units 1-6) are characterized by fine-scale layering, whereas overlying units (their 7-10) have a more massive appearance and generally lighter tone; such a transition was previously noted by Malin \& Edgett (2000) as characteristic of several interior layered deposits in Valles Marineris. Beds above and below the unconformity were grouped by Milliken et al. (2010) as the Upper and Lower formations, respectively. Lower formation beds typically dip $2-4^{\circ}$ north/northwestward, possibly conforming to pre-existing topography (Le Deit et al. 2011b), and can be further divided into lower, middle and upper members (Milliken et al. 2010). The lower member, approximately equivalent to units 1-2 of Edgett \& Malin (2001), is $>100 \mathrm{~m}$ thick and transitions from massive, lighttoned sulphate-bearing strata in its lowest exposures to more thinly bedded, recessive smectite clay-bearing strata upsection (Milliken et al. 2010); some lower member strata exhibit possible cross-bedding textures (Figs. 4(a) and (b)). The middle member (approximately unit 3 of Edgett \& Malin 2001) is $\sim 150 \mathrm{~m}$ thick and consists of intermediate-toned recessive beds containing both sulphates and clays, capped by a smooth dark 'marker bed' traceable from one edge of the mound to the other edge $\sim 75 \mathrm{~km}$ away (Milliken et al. 2010). The upper member (approximately unit 6 in Edgett \& Malin 2001) is several hundred metres thick, with mostly light-toned massive strata and sulphate spectral signatures that weaken upsection. It should be noted that a 'massive' or 'thinly bedded' appearance in orbital images does not constrain the thickness of the thinnest beds (perhaps centimetre-scale) or laminae within each unit (Milliken et al. 2010).

Strata of the kilometres-thick Upper formation in Mt. Sharp dip more steeply $\left(\sim 5-10^{\circ}\right)$ towards the north-northeast (Thomson et al. 2011) and in some locations have highly regular thicknesses (Lewis \& Aharonson 2011). Successive strata show virtually no albedo contrasts and all appear spectrally similar to Martian dust (Milliken et al. 2010), although both of these features may partly reflect the millimetre-to-centimetre-scale dust cover ubiquitous on the upper mound (Pelkey \& Jakosky 2002). The depositional surface at the base of the Upper formation (i.e. the eroded upper boundary of the Lower formation) dips $\sim 12^{\circ}$ down 

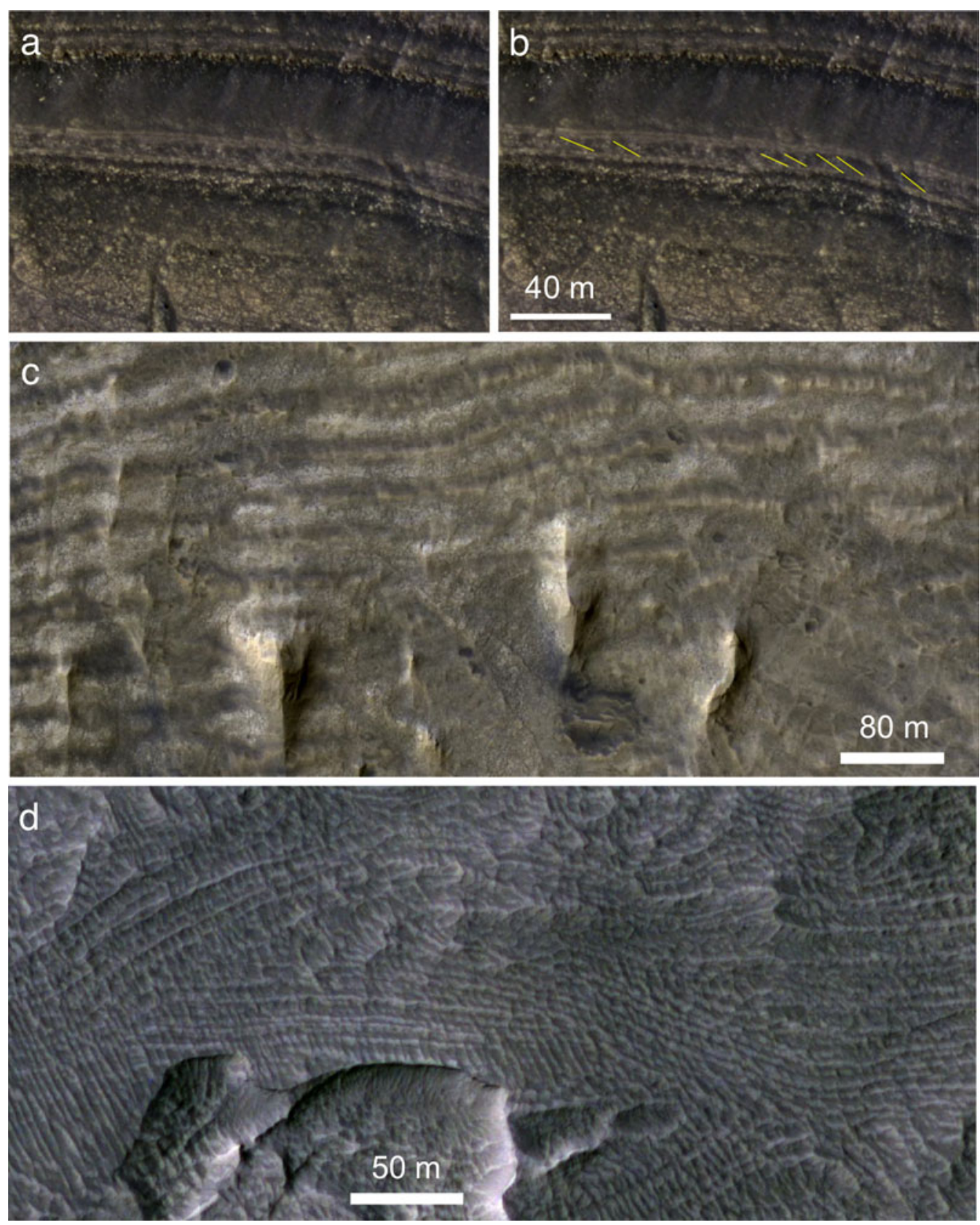

Fig. 4. (a) Possible Lower formation cross-beds exposed in wall of largest canyon on western Mt. Sharp; the oblique linear features are outlined in (b). See Fig. 6c for context (HiRISE PSP_007501_1750). (c) 'Corrugated' or ridged texture of rocks flanking the same canyon (HiRISE PSP_008147_1750). Compare with Fig. 23 of Anderson \& Bell (2010). (d) Apparent angular unconformities in the Upper formation, interpreted as Aeolian cross-strata (HiRISE PSP_001620_1750). Compare with Fig. 30 of Anderson \& Bell (2010).

towards the northwest, at least along the northwest edge of Mt. Sharp (Thomson et al. 2011). A 'scalloped' texture is observed on some portions of the upper mound (Anderson \& Bell 2010), reminiscent of dusty volcanic terrains and older wind-eroded deposits interpreted as 'duststone' elsewhere on Mars (Bridges et al. 2010). Some strata have a ridged texture in plan view (Fig. 4(c)) that has been interpreted as a constructional landform, specifically subaqueous or subaerial bed forms (Malin et al. 2010). There is disagreement over whether the outcrop in Fig. 4(c) is part of the Upper or Lower formation (Anderson \& Bell 2010; Thomson et al. 2011;
Le Deit et al. 2011b), but as Anderson \& Bell (2010) note, similar textures are also observed in younger materials embaying Mt. Sharp. Montgomery et al. (2012) have recently inferred an erosional origin for landforms of similar appearance and scale elsewhere on Mars, which would be consistent with the north-south orientation of yardang-like structures carved into strata overlying the ridged material (Fig. 4(c)). Definitive interpretation of these landforms may require direct observation of their centimetre-scale sedimentary structures with a landed mission. In the uppermost portion of the Upper formation, apparent cross-beds exposed in 
cross-section (e.g. Fig. 4(d)) provide seemingly less ambiguous evidence of Aeolian deposition (Anderson \& Bell 2010).

Pelkey \& Jakosky (2002) inferred an intermediate thermal inertia of $\sim 340 \mathrm{~J} \mathrm{~m}^{-2} \mathrm{~s}^{-0.5} \mathrm{~K}^{-1}$ for the material underlying the dusty surface cover on Mt. Sharp; this value is consistent with lightly indurated material and comparable to sulphate-bearing layered deposits in many other regions of Mars (Arvidson et al. 2003; Mangold et al. 2008; Chojnacki \& Hynek 2008; Wray et al. 2011). The Mt. Sharp strata also resemble those in Valles Marineris, the chaos terrains and craters in Arabia Terra both morphologically (Le Deit et al. 2011a) and spectrally: as in many equatorial layered deposits (e.g. Gendrin et al. 2005), both polyhydrated and monohydrated varieties are observed, with features consistent with $\mathrm{Mg}$-sulphates $\mathrm{MgSO}_{4} \cdot n \mathrm{H}_{2} \mathrm{O}$, for $n>1$ and $n=1$, respectively (Milliken et al. 2010). Hydrated $\mathrm{Ca}$ - and $\mathrm{Na}$-sulphates have distinct $\mathrm{OH} / \mathrm{H}_{2} \mathrm{O}$-related spectral features (e.g. Crowley 1991) that are not yet definitively observed in Gale and $\mathrm{Fe}^{2+}$ or $\mathrm{Fe}^{3+}$-sulphates have visible/nearIR electronic absorptions (Cloutis et al. 2006) that are also not observed (Milliken et al. 2010; Thomson et al. 2011), although the Fe-related absorptions can be masked by coatings or surficial dust. The acid hydroxylated sulphates jarosite and alunite are spectrally distinct, and also not yet observed in Gale. However, in situ measurements of Meridiani Planum outcrops reveal $\sim 20 \%$ Mg-sulphate and $\sim 10 \%$ each of Ca-sulphate and jarosite (Clark et al. 2005; Glotch et al. 2006), even though orbital spectra of Meridiani outcrops show clear evidence for only the $\mathrm{Mg}$-sulphate component (Arvidson et al. 2005; Poulet et al. 2008; Wiseman et al. 2010). A mixed sulphate composition in Gale, perhaps similar to that in Meridiani, thus cannot be ruled out. In fact, a broad band centred at $\sim 2.2 \mu \mathrm{m}$ in spectra from some sulphate-bearing outcrops in Gale (Fig. 3; see also Fig. 3(d) from Milliken et al. 2010) may be consistent with the $\sim 2.21 \mu \mathrm{m}$ band of gypsum $\left(\mathrm{CaSO}_{4} \cdot 2 \mathrm{H}_{2} \mathrm{O}\right)$ and/or the $\mathrm{Si}-\mathrm{OH}$ absorption in opaline silica. A similar feature at $\sim 2.2 \mu \mathrm{m}$ is found in some spectra from the sulphate-bearing terrains in Meridiani (Fig. 2(b) of Wray et al. 2009), where the rocks contain both Ca-sulphates and amorphous silica (Clark et al. 2005; Glotch et al. 2006). Minor pyroxene may also be present in the siliciclastic component of Meridiani sulphate-rich rocks (Clark et al. 2005), and similarly some sulphate-bearing strata in Gale show evidence for a pyroxene component (Anderson \& Bell 2010; Milliken et al. 2010). Finally, some sulphate-bearing strata in Gale show evidence for crystalline red haematite (Milliken et al. 2010), perhaps analogous to $<30 \mu \mathrm{m}$ haematite in Meridiani outcrop matrix (Clark et al. 2005; Fleischer et al. 2010). Unlike Meridiani, Gale shows no evidence for substantial accumulations of crystalline grey haematite in surface lag deposits (Rogers \& Bandfield 2009).

It is challenging to constrain the abundance of sulphates in Mt. Sharp strata based on orbital data alone. Their nondetection at thermal IR wavelengths has been used to argue for abundances $<15 \%$ (and even lower limits on carbonate abundances; Stockstill et al. 2005, 2007). However, sulphates are not clearly detected at these wavelengths even in Meridiani Planum where their abundances in outcrop reach $\sim 40 \%$; indeed, these sulphates escape even near-IR detection across much of Meridiani (Arvidsonet al. 2006; Poulet et al. 2008), so their near-IR detection in Gale may indicate abundances of at least tens of percent, and/or outcrop surfaces that are less desiccated, coated or covered with surficial fines than those in Meridiani. Thermal IR spectral deconvolutions do allow for $\sim 12 \%$ sulphate in the dark sands bordering Mt. Sharp (Rogers \& Bandfield 2009), although this does not exceed formal detection limits. Mt. Sharp strata would be a plausible source for any sulphates in the sands downslope.

The phyllosilicates in the Lower formation at Gale are spectrally consistent with the $\mathrm{Fe}^{3+}$-smectite nontronite (Milliken et al. 2010). An unusual feature of these spectra relative to most $\mathrm{Fe} / \mathrm{Mg}$-phyllosilicates detected on Mars is a shoulder at $\sim 2.23 \mu \mathrm{m}$, indicating substitution of $\mathrm{Al}^{3+}$ for $\mathrm{Fe}^{3+}$ in nontronite and/or a distinct Al-phyllosilicate component (Milliken et al. 2010). The smectites in Mt. Sharp also show minimal spectral evidence for illitization or chloritization, unlike the majority of Fe/Mg-phyllosilicates in the Noachian highlands (Milliken et al. 2011). Modelling of the near-IR spectra of clay-bearing layers in Mt. Sharp appears to constrain the smectite abundances to $<30 \%$, with the remaining $70+\%$ composed of primary basaltic minerals and perhaps some surficial dust (Poulet \& Carter 2012). Thermal IR spectroscopy may further constrain the phyllosilicate abundances to $<10-20 \%$ (Rogers \& Bandfield 2009), but the available data may also be limited by spatial resolution and/or surficial fines that dilute the spectral influence of the phyllosilicates.

\section{Surface and subsurface water flow}

Independent of how the Mt. Sharp strata were originally deposited, Gale exhibits much morphologic evidence for their subsequent modification by liquid water or brines, both on the surface and beneath it. Firstly, features interpreted as Aeolian cross-strata suggest fairly dry conditions at the time of deposition, but for these features to have been preserved in the rock record likely required some degree of subsequent cementation, presumably by grains precipitated from percolating fluids (although dry compaction may also have been significant in Gale after burial under kilometres of overlying strata). Polygonal ridge networks (Fig. 5), interpreted as erosionally resistant fractures that have been cemented or filled, provide additional evidence for groundwater flow after sedimentation (Anderson \& Bell 2010; Thomson et al. 2011). Some of these have a double-ridged morphology wherein the central dark zone could be the fracture itself (Anderson \& Bell 2010). Similar features in Valles Marineris (Okubo \& McEwen 2007) and other aqueous deposits at low latitudes (e.g. Wray et al. 2008; Wray \& Ehlmann 2011) have also been interpreted as evidence for subsurface fluid migration along fractures, or at least as structural discontinuities that would have directed the flow of any subsurface fluids present after they formed (Okubo et al. 2009).

Dozens of small channels line the crater walls and the edges of Mt. Sharp (Cabrol et al. 1999; Pelkey et al. 2004; 


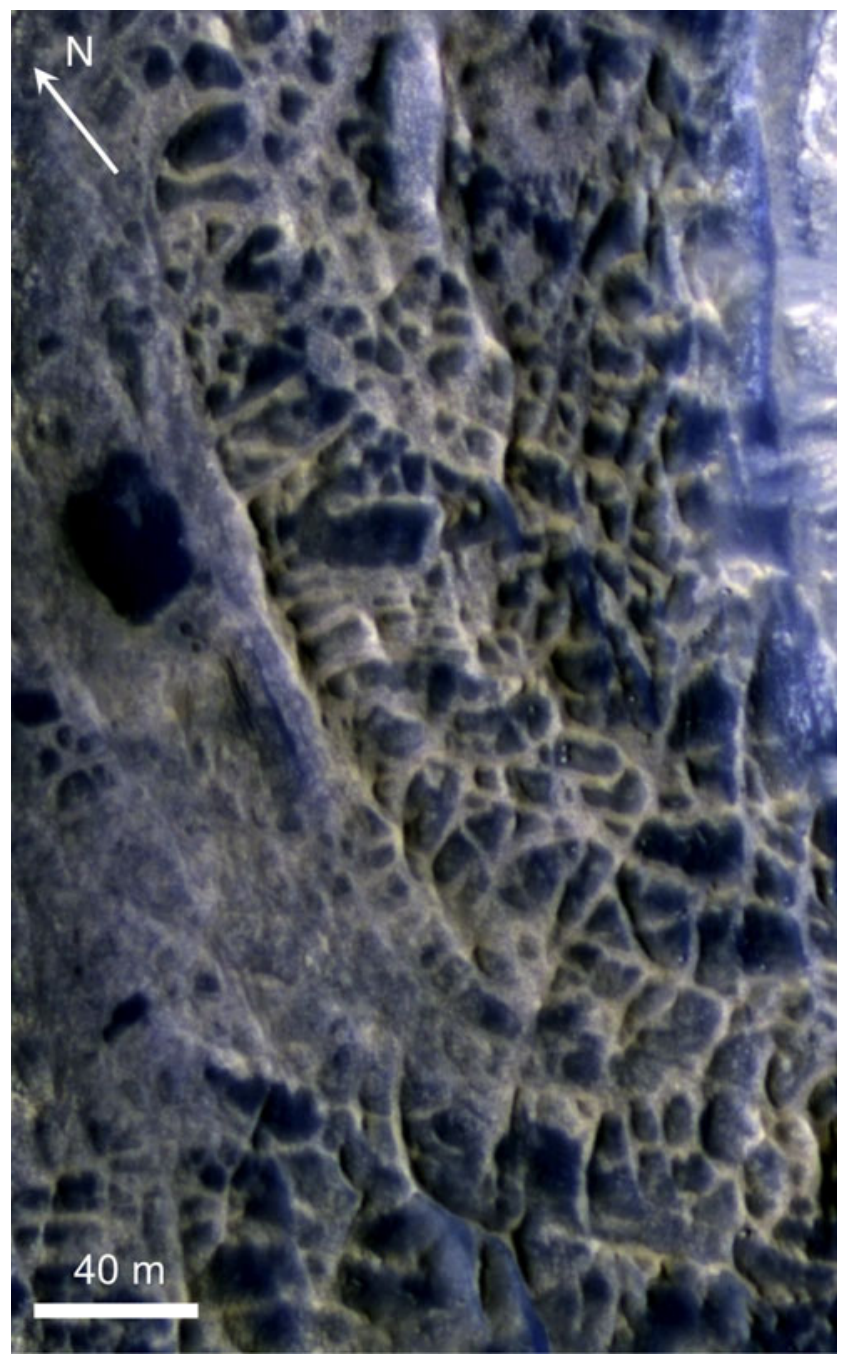

Fig. 5. Polygonal ridge networks interpreted as cemented or filled fractures (HiRISE PSP_001752_1750).

Anderson \& Bell 2010). Most of these terminate on the modern crater floor, suggesting they did not debouch into a lake with water level significantly above the current floor elevation (Pelkey et al. 2004). Only one channel enters Gale from beyond the crater rim, and may be part of a regional drainage system originating near Herschel basin (Fig. 1) hundreds of kilometres to the southwest (Irwin et al. 2005). Gale crater ejecta appear to have partly buried this valley system, implying that it was first active prior to Gale's formation and that a distinct late fluvial episode was responsible for the breaching of Gale's rim (Irwin et al. 2005). This valley's mouth coincides with the large dune field on Gale's western floor. Many of the smaller channels on both the crater walls and Mt. Sharp have fan-shaped deposits at their mouths, including a relatively large, low-relief example just north of Curiosity's landing ellipse (Anderson \& Bell 2010). These are generally interpreted as alluvial fans, although a deltaic origin may be possible for some (Le Deit et al. 2011b), including a large, scarp-fronted deposit on the south-southwest side of Mt. Sharp, which would imply a water level near $-3300 \mathrm{~m}$ at the time it formed (Irwin et al. 2005).
Other canyons - including one incised into Mt. Sharp near the landing ellipse - have mouths at much lower elevations, requiring a lower lake level, if any (Sumner 2011). The northnortheast edge of Mt. Sharp has different fan-shaped landforms with a more lobate appearance, interpreted as probable landslide or debris flow deposits (Anderson \& Bell 2010; Le Deit et al. 2011b). Sinuous ridges interpreted as resistant fluvial channel-filling material are found extending from crater wall channels, on some fans, and as isolated erosional remnants all the way down to the lowest elevations on the crater floor (Anderson \& Bell 2010). Linear ridges are found in some alcoves of the large canyons on western Mt. Sharp (Fig. 6); these have also been interpreted as fluvial channel deposits (Anderson \& Bell 2010; Thomson et al. 2011), or some that lack tributary valleys could be clastic dikes intruded along structural weaknesses where erosion was subsequently enhanced, forming the alcoves. Regardless, a more sinuous light-toned deposit on the floor of the largest canyon likely consists of fluvial channel sediments. No canyons extend significantly above the Lower formation, and possible evidence for exhumation of the largest canyon (Anderson \& Bell 2010) is consistent with fluvial activity in Gale having ceased prior to deposition of Upper formation strata. Later Aeolian erosion of Mt. Sharp has also been significant, as evidenced by the yardang-like morphology seen on many Upper and Lower formation strata (Cabrol et al. 1999; Anderson \& Bell 2010; Thomson et al. 2011).

\section{Mound formation hypotheses}

The diverse textures and large apparent volume of Mt. Sharp strata have led to many different hypotheses for their origin. At most, only the Lower formation strata can be from a lake filling Gale because the mound's summit exceeds the height of the northern crater rim by kilometres (Irwin et al. 2004). Cabrol et al. (1999) used Viking orbiter data and early topographic profiles from MOLA to infer several stages of lacustrine activity in Gale. They argued for an early lacustrine phase resulting from impact-induced hydrothermal activity, and for later (Amazonian) lakes sourced from subsurface aquifer drainage and from overspilling of a large lake or sea filling Elysium Planitia. The early lacustrine phase may be geologically inevitable for a crater of Gale's size (Rathbun \& Squyres 2002; Schwenzer et al. 2012), but preserved evidence for the products of impact-induced hydrothermalism remains elusive in the great majority of Martian craters (e.g. Ehlmann et al. 2011b), even those that have experienced much less subsequent erosion and burial than Gale. Elysium Planitia, while initially interpreted as a Middle Amazonian paleolake (e. g. Scott \& Chapman 1995), has been reinterpreted in the past decade as filled with lava flows rather than lake sediments (e.g., Hartmann \& Berman 2000; Boisson et al. 2009; Jaeger et al. 2010). Post-Viking era topography precludes an isolated Elysium sea during the Amazonian, instead requiring a vast ocean filling the northern plains at this time to reach a water level high enough to breach Gale's northern rim, which shows no evidence of such a breach (Irwin et al. 2005). Subsurface aquifer drainage and/or overland flow from much smaller 

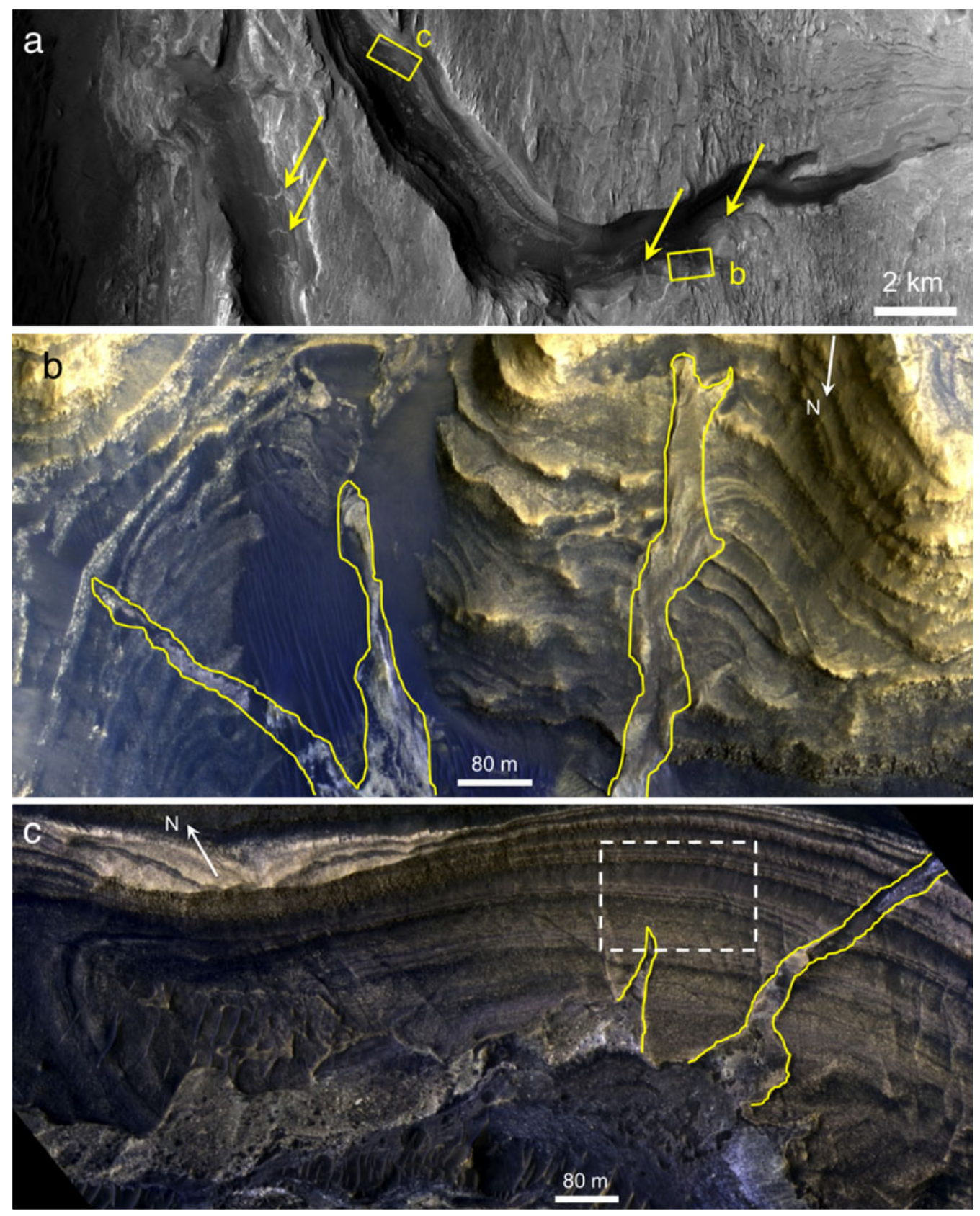

Fig. 6. (a) Bright linear ridges (arrows) interpreted as fluvial channel deposits or clastic dikes on walls of the largest canyons of western Mt. Sharp; boxes show locations of panels $\mathrm{b}$ and c. From a mosaic of CTX and HiRISE images. Compare with Fig. 5 of Thomson et al. (2011). (b) Bright linear ridges outlined in yellow (HiRISE ESP_012340_1750). (c) Bright linear ridges that appear to merge with sinuous canyon floor deposit downslope; location of Fig. 4a is outlined in white (HiRISE PSP_007501_1750).

drainage areas therefore remain the most likely sources for paleolake water in Gale after its formation.

The minimal fluvial dissection of Aeolis Mensae (Irwin et al. 2004) provides little evidence for a large aquifer there, originally hypothesized as a major source for paleolakes in Elysium and Gale (Cabrol et al. 1999). However, the great depth of Gale and its location downslope from a precipitation zone predicted by global climate modelling implies it would have been a regional optimum for groundwater emergence (Andrews-Hanna et al. 2012a), potentially explaining why
Gale's thick sulphate deposits are apparently unique within its region, unlike the much more widespread sulphates in Valles Marineris and Meridiani Planum (e.g. Ehlmann 2012). Groundwater-fed evaporites could have accumulated up to the approximate observed upper boundary of Lower formation strata, after which further growth would naturally have slowed by an order of magnitude (Andrews-Hanna et al. 2012b). Cratering and fluvial erosion of the Lower formation may then have occurred until a new climatic/sedimentary regime allowed building of the Upper formation. A warmer early climate may 
have allowed groundwater flow, or alternatively the melting of equatorial ground ice (e.g. Paige 1992; Schorghofer 2007) may have provided water only occasionally during high-obliquity periods under a climate with cold average conditions like those existing today (Cadieux \& Kah 2011).

The groundwater upwelling model may imply a similar history for Gale's Lower formation as for the Burns formation in Meridiani Planum (Andrews-Hanna et al. 2007); this hypothesis would be supported by the substantial similarity in spectral, morphological and thermophysical characteristics of the two formations as described above. Evaporite minerals in the Burns formation are inferred to have formed via alteration of basalts, further altered during deposition in playas, and later experienced multiple episodes of diagenetic overprinting (McLennan et al. 2005). The strata explored by Opportunity were deposited in Aeolian dunes, sand sheets and shallow interdune playas (Grotzinger et al. 2005; Metz et al. 2009; Squyres et al. 2009). Similar facies could dominate much of Gale's Lower formation, but the 1-2 orders of magnitude thicker section for Curiosity to explore may lead to discovery of additional facies, such as buried fluvial deposits and/or deeper lake sediments. Sumner (2011) argued that some exposed strata in Mt. Sharp are likely lacustrine based on their bedding geometries and elevations apparently similar to those of some fluvial channel mouths. Lakes on Mars are not expected to preserve shorelines unless active during the late Hesperian or more recently, and even in that case the relevant features may be at the metre scale, requiring detailed analyses of the highest-resolution images available from orbit or from a landed mission (Irwin \& Zimbelman 2012). Definitive evidence for lake sediments in Gale crater must await in situ observations of sedimentary textures, grain sizes and compositions (e.g. Squyres et al. 2004a), which Curiosity will make.

A colder and largely drier proposed scenario is that sedimentation and alteration in Mt. Sharp occurred due to solid-state greenhouse melting within ice sheets (Niles \& Michalski 2009, 2012) or seasonal snowmelt (Clow 1987; Kite et al. 2012a) during high-obliquity times when ice would have migrated from the poles to the equator (Jakosky \& Carr 1985). Snowmelt would be favoured under only a somewhat thicker ( $\sim 100$ mbar) atmosphere, and could approximately reproduce the global distribution of Martian sedimentary rocks, including Gale as a regionally unique depocenter; however, snowmelt is only predicted at the lower elevations of Mt. Sharp (Kite et al. 2012a). Minor melting within ice sheets may occur even under a modern climate, as it appears the most likely source for late Amazonian sulphates bounding the north polar cap (e.g. Massé et al. 2010). Both models have been proposed for building the entire Gale mound, but neither naturally explains the transition in composition, bedding characteristics and fluvial dissection from the Lower to the Upper formation.

Milliken et al. (2010) proposed that the clay and sulphate stratigraphy of Mt. Sharp records a global change in aqueous chemistry inferred by Bibring et al. (2006) from global observations. The lowest exposed strata in Mt. Sharp are sulphate-bearing rather than clay-bearing, but this is not unprecedented for Noachian clay sections, and those sulphates may not necessarily predate the clay minerals (Wray et al. 2010). However, Fe/Mg-smectite formation has been described as more characteristic of the pre- and early-to-mid Noachian (Bibring et al. 2006; Ehlmann et al. 2011a) than of the late Noachian/early Hesperian Epoch in which Gale's Lower formation accumulated. The unique spectral characteristics of Gale's smectites relative to most Noachian phyllosilicates may support an alternative interpretation that they represent a relatively late and rare episode of localized alkaline or weakly acidic aqueous conditions that allowed phyllosilicate formation during an era when sulphate formation was much more common, perhaps analogous to phyllosilicates inferred in the sulphate-bearing terrains of Meridiani Planum both from orbit (Poulet et al. 2008) and in situ (Glotch et al. 2006), and to terrestrial systems that form sulphates and clay minerals simultaneously (Baldridge et al. 2009). The apparently high $\mathrm{Al}$ content of smectites in Gale crater compared with most Noachian phyllosilicates is additionally consistent with global observations of a distinct Al-phyllosilicate formation episode in the late Noachian (e.g. Ehlmann et al. 2011a), although no clear stratigraphy of Al-phyllosilicates overlying Fe/Mg-phyllosilicates (as found widely across late Noachian Mars) has been observed at Gale. Preservation of smectites at the base of Mt. Sharp may imply minimal availability of liquid water during most of the period since they accumulated (Tosca \& Knoll 2009), and/or that the exposed smectites at the mound's edge were never buried kilometres underground.

The Upper formation may have a distinct origin. Malin \& Edgett (2000) first suggested that Gale had once been completely filled and buried by sedimentary deposits that were subsequently removed from the crater walls inward, a process for which they argued by comparing the present distributions of sedimentary rocks in a number of craters across Mars. An outlier outcrop of layered material noted by Anderson \& Bell (2010) suggests at least a slightly greater prior extent for layered deposits in Gale beyond the present extent of Mt. Sharp, although such outliers are rare (Le Deit et al. 2012). Processes that could have buried Gale and its surroundings include pyroclastic deposition as part of the MFF (Thomson et al. 2008, 2011; Zimbelman \& Scheidt 2012), Aeolian dune migration as suggested by observed crossbeds (Anderson \& Bell 2010), and/or airfall dust accumulation by analogy to similar regularly bedded deposits in craters of Arabia Terra (Lewis et al. 2008b). If obliquity cycles drove accumulation of the regularly bedded portion, then its several hundred metres thickness (Lewis \& Aharonson 2011) may have accumulated over a period of a few to tens of millions of years (Lewis et al. 2010). If much of the Upper formation is MFF material sourced from Apollinaris Patera, then its thickness may have implications for the atmospheric pressure during the late Hesperian. Kerber et al. (2012) simulated the dispersal of Apollinaris pyroclasts as a function of paleo-atmospheric pressure, and found that the thickest deposits (approximately several hundreds of metres) are predicted over Gale for several hundred mbar atmospheres; thinner atmospheres 
spread pyroclasts too thinly across a broader region, whereas thicker ( $>1$ bar) atmospheres prevent significant accumulation at Gale's distance $(\sim 2000 \mathrm{~km})$ westward of Apollinaris. This would be consistent with inferences of a $>100$ mbar atmosphere at the time of pyroclastic deposition in Gusev crater (Manga et al. 2012), which is just south of Apollinaris.

A challenge for scenarios involving past burial of Gale is the high erosion rate required to remove at least $\sim 5 \mathrm{~km}$ of sedimentary rocks from the moat surrounding Mt. Sharp. The highest inferred post-Noachian erosion rates for light-toned layered deposits on Mars are $\sim 1-3 \mu \mathrm{m} /$ year during the early Hesperian (e.g. Golombek et al. 2006; Zabrusky et al. 2012), although it should be noted that the abrasion rates at sites of most active sand transport today could be an order of magnitude higher (Bridges et al. 2012b). At $3 \mu \mathrm{m} / \mathrm{year}$, a $\sim 5 \mathrm{~km}$ deep moat would require $\sim 1.7 \mathrm{Ga}$ to form, thus extending the erosional period into the Amazonian (when rates were likely even lower) and in conflict with the early Hesperian exposure age of the crater floor unit onlapping the mound (Thomson et al. 2011). Alternative models have therefore been proposed that eliminate the need for past burial of Gale. Rossi et al. (2008) proposed a central spring origin for the entire mound, with total height 1-2 orders of magnitude greater than the thickest spring deposits found on Earth (Crumpler 2003), but the presence of some beds traceable over tens of kilometres is inconsistent with sedimentary structures typically found in spring mounds (Anderson \& Bell 2010). Noting the outward dips of beds on both sides of Mt. Sharp (specifically in the Lower formation) and the previously observed importance of slope winds in shaping Martian sedimentary deposits, Kite et al. (2012b) introduce a model that could build the entire central mound via successive draping of airfall sediment and erosion dominated by slope winds down the growing mound, perhaps similar to some processes proposed for forming ice mounds in craters surrounding the north pole (Russell et al. 2004; Brown et al. 2008; Conway et al. 2012). Preservation of the moat around the mound in this model rules out a major role for sedimentary processes that tend to fill in topographic lows, such as fluvio-lacustrine sedimentation (Kite et al. 2012b). However, some layered, fractured and indurated deposits within the landing ellipse (Anderson \& Bell 2010) could have formed in moat-filling lakes or alluvial fans.

\section{Astrobiological potential}

Astrobiology is the overarching scientific thrust currently driving the planning of future Mars missions (e.g. MEPAG ND-SAG 2008). The potential for finding evidence of past or present life in Gale crater has two components: environmental habitability and potential for preserving biosignatures. Habitability is generally thought to require (1) liquid water, (2) key chemical elements used by life (e.g. carbon) and (3) energy source(s) for metabolic activity. Habitability does not imply life, but if life did exist, then the rock record's subsequent preservation of its evidence requires low levels of chemical and physical change to the biosignature-bearing materials.
Liquid water has clearly been present in Gale crater. Both the crater walls and Mt. Sharp are dissected by fluvial channels, and fluvial sediments are preserved in some of these, with several authors also suggesting lacustrine deposits may be present in Mt. Sharp or Aeolis Palus, exposed at the modern surface for interrogation by Curiosity or other landed missions. High salinity (Tosca et al. 2008a) and acidity (Squyres et al. 2004b) have been interpreted as challenges for life in the mineralogically similar Burns Formation, but these concerns are based on minerals (chlorides and jarosite, respectively) that might have formed relatively late in Meridiani's aqueous history, and which in any case are not yet detected in Gale crater. The presence of carbon - and some other elements essential to life on Earth, such as nitrogen and phosphorus - is unconstrained from orbital observations of Gale. Carbonate minerals detected elsewhere on Mars have not yet been identified here (Ehlmann 2012), and so far there is no evidence for or against methane emissions from the crater (see profiles a and b in Fig. 2C of Mumma et al. 2009). The issue of energy sources is more complex; certainly the mineralogic stratigraphy in Gale provides evidence for chemical change, but whether redox gradients of the types that life can exploit (e.g. Nealson 1997) were ever present at a given time remains unknown. The sulphur (sulphate) and iron mineralogy (haematite and nontronite) suggest purely oxidizing conditions during the last few aqueous episodes that influenced Mt. Sharp, although nontronite in particular may require initially reducing conditions to form ferrous smectite as a precursor phase (Tosca et al. 2008b). Reduced iron phases such as olivine and pyroxene are observed in the crater, but so far only in mobile sands. Prospects for photosynthetic life are even more poorly constrained, given the uncertainty of when such life emerged on Earth relative to the age of materials in Gale (e.g. Buick 2008) and the likelihood that an optically thick ice cover would form rapidly over any Martian lake under a climate similar to today's (e.g. Squyres 1989).

Challenges to preservation of organic biosignatures (and to organics delivered exogenously or formed through igneous processes - e.g. Steele et al. 2012) at the Martian surface include Solar ultraviolet radiation (e.g. Stoker \& Bullock 1997) and oxidizing compounds (e.g. Benner et al. 2000). A thorough discussion of possible oxidants, ultraviolet and other mechanisms affecting Martian organics is given by ten Kate (2010). Ultraviolet photons penetrate only microns beneath the surface (e.g. ten Kate 2010), but Solar and galactic cosmic rays can penetrate $\sim 1-2 \mathrm{~m}$ (Pavlov et al. 2012). Cosmic rays destroy heavy ( $\sim 500 \mathrm{amu}$ ) organics to a depth of $\sim 5 \mathrm{~cm}$ (Curiosity's drilling depth) within $200 \mathrm{Myr}$ (Pavlov et al. 2012). Fortunately, these ionization rates would be outpaced even by the low Amazonian erosion rates of $\sim 1-10 \mathrm{~nm} /$ year inferred for (Gale-like?) sedimentary rocks in Meridiani (Golombek et al. 2006). Still, the most promising targets may be small impact craters, both because relatively recent impacts could have ejected or exposed rocks from beneath the ionized layer and because erosion may be locally accelerated a hundred- or thousand-fold above the background level following impacts (Golombek et al. 2010). Regardless, the low 
elevation and consequently thick atmosphere over Aeolis Palus and the Lower formation imply a relatively low cosmic ray flux compared with most Martian terrains (e.g. Saganti et al. 2004).

Diagenesis under oxidizing conditions such as those inferred in Meridiani can also destroy organics (Sumner 2004), but the non-detection of crystalline grey haematite in Gale (as opposed to Meridiani) could indicate a lesser degree of oxidizing diagenesis, consistent with the preservation of unaltered smectites in the Lower formation (Tosca \& Knoll 2009). Smectites form in neutral-to-alkaline fluids (e.g. Chevrier et al. 2007), bind and thereby concentrate organics, and upon compaction they can form impermeable layers that are comparatively resistant to later alteration in the subsurface (e.g. Summons et al. 2011). Gale's smectite-bearing layers may therefore be among its most important targets for astrobiological exploration, as would any other deposits formed in a persistent lacustrine setting. More broadly, Mt. Sharp provides the opportunity to evaluate habitability and preservation in both surface and subsurface aqueous paleoenvironments, and to assess how these parameters evolved over a span of time.

\section{Future exploration}

Studies of Gale crater based on orbital data have revealed much about its history and have motivated landing there, but some additional questions may be resolvable from orbit. High Resolution Imaging Science Experiment (HiRISE) images now cover $\sim 50 \%$ of Mt. Sharp at $\sim 30 \mathrm{~cm} /$ pixel. These $>10^{10}$ pixels should be more closely examined for textures potentially diagnostic of depositional processes (e.g. Fig. 4). Compositional information from the Compact Reconnaissance Imaging Spectrometer for Mars (CRISM) is available at $\sim 18 \mathrm{~m} /$ pixel over a similar fraction of the mound, potentially allowing assessment of whether the mineral stratigraphy discovered on the northwest slope (Milliken et al. 2010) is ubiquitous across the Lower formation. One open question is the relationship of polyhydrated sulphates to monohydrates. Elsewhere on Mars, such varying sulphate hydration states have been attributed to (1) differing water activity or temperature in the depositional environment (e.g. Roach et al. 2009), (2) diagenesis of polyhydrates to produce monohydrates at depth (e.g. Murchie et al. 2009a, b) and/or (3) recent surficial hydration state changes (Mangold et al. 2008). A careful analysis of CRISM data coordinated with HiRISE-scale topography might elucidate this mineral stratigraphy and provide new insights into the history of Gale's sulphate-bearing layers. New 'superresolution' CRISM data (down to $\sim 3 \mathrm{~m}$ pixel width) acquired via oversampling the surface in the along-track direction (Fraeman et al. 2012) may help to unravel subtleties of the sulphate stratigraphy and the relationship of sulphates to smectites - e.g. are they finely interbedded or do they co-occur in the same strata?

To certify Curiosity's landing ellipse and most likely drive destinations as safe to land on and traverse, these areas have received unprecedented coverage with CRISM and HiRISE prior to landing (Golombek et al. 2012). This large dataset should be examined more thoroughly and used to produce detailed geologic maps that can guide Curiosity's exploration to key locations for hypothesis testing. An unfortunate side effect of this focus on preparing for Curiosity's mission is that other portions of Gale (especially the crater rim) and the terrain surrounding it have been comparatively under-imaged. Since Curiosity will likely drive straight towards Mt. Sharp and never approach the crater wall/rim, orbital data from areas with relatively low dust cover (and float rocks analysed in situ) will remain the only resources for determining the composition of pre-Gale rocks that might have been sediment sources for Mt. Sharp. Analyses to date reveal no local or regional sources for the mound's sulphates or nontronite, but further work is warranted. Additional imaging and analysis of other craters near Gale and of the intercrater plains should also be prioritized to determine whether the Mt. Sharp deposits are entirely unique on this side of Mars, or can be placed within a broader regional context.

Curiosity's instrument payload (Grotzinger et al. 2012) will resolve many other first-order science questions about Gale that can never be answered from orbit. Curiosity's primary method of compositional remote sensing (laser-induced breakdown spectroscopy via ChemCam, as opposed to passive IR spectroscopy) is well suited for the high dust cover present in some parts of Gale crater. Combining ChemCam with stereo multispectral imaging via Mastcam at wavelengths informative about iron mineralogy and hydration (Bell et al. 2012) will allow substantial refinement of the compositional stratigraphy at scales not resolvable by HiRISE. The Alpha Particle X-ray Spectrometer (APXS) will provide revolutionary insights into bulk chemistry and whether alteration has been isochemical (Ming et al. 2008) or otherwise, whereas MArs Hand Lens Imager (MAHLI) will constrain sediment grain shapes and size distributions, sedimentary and diagenetic textures. CheMin will reveal the minerals that accompany sulphates and clays in the strata of the Lower formation, while Sample Analysis at Mars (SAM) will help nail down the composition of volatile components, both inorganic and potentially organic. In combination, Curiosity's observations can be used to discriminate between the many formation hypotheses for Mt. Sharp.

Beyond Curiosity, sample return is a high priority for future Mars exploration (e.g. Space Studies Board 2011). Should we return samples from Gale crater? Certainly the diversity of both altered and intact igneous rocks appears greater from orbit at some other known sites (e.g. Ehlmann \& Mustard 2012). However, the Mt. Sharp reference section, if it can indeed be related to environmental change on a regional or global scale, could be a 'Rosetta stone' for the Hesperian Period on Mars, given the many contextual measurements that Curiosity will make. Ultimately, the decision whether to return samples from Gale will be likely based heavily on the results of Curiosity's investigations into whether and when the crater hosted habitable environments, and whether any biosignatures might be preserved until the present day. 


\section{Acknowledgements}

The author thanks Inge ten Kate for inviting this review, for valuable feedback, and for very efficient editorial handling of the manuscript. Angelo Pio Rossi and Brad Thomson provided constructive reviews that significantly improved the paper. The text was informed by discussions with many scientific colleagues, notably including Ken Edgett, Ralph Milliken, John Grotzinger, Dawn Sumner, Gregg Swayze and Edwin Kite. I also thank Wendy Calvin for collegial support.

\section{References}

Anderson, R.B. \& Bell, J.F. III (2010). Mars 5, 76-128.

Andrews-Hanna, J.C., Phillips, R.J. \& Zuber, M.T. (2007). Nature 446, 163-166.

Andrews-Hanna, J.C., Soto, A. \& Richardson, M.I. (2012a). In 43rd Lunar and Planetary Science Conf., abstract no. 2706.

Andrews-Hanna, J.C., Soto, A. \& Richardson, M.I. (2012b). In Third Conf. Early Mars, abstract no. 7038.

Arvidson, R.E., Seelos, F.P. IV, Deal, K.S., Koeppen, W.C., Snider, N.O., Kieniewicz, J.M., Hynek, B.M., Mellon, M.T. \& Garvin, J.B. (2003). J. Geophys. Res. 108(E12), 8073.

Arvidson, R.E., Poulet, F., Bibring, J.-P., Wolff, M., Gendrin, A., Morris, R. V., Freeman, J.J., Langevin, Y., Mangold, N. \& Bellucci, G. (2005). Science 307, 1591-1594.

Arvidson, R.E., Poulet, F., Morris, R.V., Bibring, J.-P., Bell, J.F. III, Squyres, S.W., Christensen, P.R., Bellucci, G., Gondet, B. \& Ehlmann, B. L. (2006). J. Geophys. Res. 111, E12S08.

Baldridge, A.M., Hook, S.J., Crowley, J.K., Marion, G.M., Kargel, J.S., Michalski, J.L., Thomson, B.J., de SouzeFilho, C.R., Bridges, N.T. \& Brown, A.J. (2009). Geophys. Res. Lett. 36, L19201.

Bell, J.F. III, Malin, M.C., Caplinger, M.A., Ravine, M.A., Godber, A.S., Jungers, M.C., Rice, M.S. \& Anderson, R.B. (2012). In 43rd Lunar and Planetary Science Conf., abstract no. 2541.

Benner, S.A., Devine, K.G., Matveeva, L.N. \& Powell, D.H. (2000). Proc. Natl. Acad. Sci. U.S.A. 97, 2425-2430.

Bibring, J.-P. et al. (2006). Science 312, 400-404.

Boisson, J. et al. (2009). J. Geophys. Res. 114, E08003.

Bradley, B.A., Sakimoto, S.E.H., Frey, H. \& Zimbelman, J.R. (2002) J. Geophys. Res. 107(E8), 5058.

Bridges, N.T. (2001). In First Landing Site Workshop for the 2003 Mars Exploration Rovers, abstract no. 9033, Mountain View, CA, 24-25 January 2001.

Bridges, N.T. et al. (2010). Icarus 205, 165-182.

Bridges, N.T. et al. (2012a). Geology 40, 31-34.

Bridges, N.T., Ayoub, F., Avouac, J.-P., Leprince, S., Lucas, A. \& Mattson, S. (2012b). Nature 485, 339-342.

Brown, A.J., Byrne, S., Tornabene, L.L. \& Roush, T. (2008). Icarus 196, 433-445.

Buick, R. (2008). Philos. Trans. R. Soc. Lond. B 363, 2731-2743.

Burr, D.M., Enga, M.-T., Williams, R.M.E., Zimbelman, J.R., Howard, A. D. \& Brennand, T.A. (2009). Icarus 200, 52-76.

Cabrol, N.A., Grin, E.A., Newsom, H.E., Landheim, R. \& McKay, C.P. (1999). Icarus 139, 235-245.

Cadieux, S.B. \& Kah, L.C. (2011). In 42nd Lunar and Planetary Science Conf., abstract no. 1265.

Carter, L.M. et al. (2009). Icarus 199, 295-302.

Chapman, C.R. \& Jones, K.L. (1977). Annu. Rev. Earth Planet. Sci. 5, 515-540.

Chevrier, V., Poulet, F. \& Bibring, J.-P. (2007). Nature 448, 60-63.

Chojnacki, M. \& Hynek, B.M. (2008). J. Geophys. Res. 113, E12005.

Clark, B.C. et al. (2005). Earth Planet. Sci. Lett. 240, 73-94.

Cloutis, E.A. et al. (2006). Icarus 184, 121-157.

Clow, G.D. (1987). Icarus 72, 95-127.
Conway, S.J., Hovius, N., Barnie, T., Besserer, J., Le Mouélic, S., Orosei, R. \& Read, N.A. (2012). Icarus 220, 174-193.

Craddock, R.A. \& Maxwell, T.A. (1993). J. Geophys. Res. 98(E2), 3453-3468.

Craddock, R.A. \& Howard, A.D. (2002). J. Geophys. Res. 107(E11), 5111.

Crowley, J.K. (1991). J. Geophys. Res. 96(B10), 16, 231-16, 240.

Crumpler, L.S. (2003). In Sixth Int. Conf. on Mars, abstract no. 3228.

Edgett, K.S. \& Malin, M.C. (2001). In 32nd Lunar and Planetary Science Conf., abstract no. 1005.

Ehlmann, B.L. (2012). In Third Conf. on Early Mars, abstract no. 7084.

Ehlmann, B.L. \& Mustard, J.F. (2012). Geophys. Res. Lett. 39, L11202.

Ehlmann, B.L., Mustard, J.F., Murchie, S.L., Bibring, J.-P., Meunier, A., Fraeman, A.A. \& Langevin, Y. (2011a). Nature 479, 53-60.

Ehlmann, B.L., Mustard, J.F., Clark, R.N., Swayze, G.A. \& Murchie, S.L. (2011b). Clays Clay Miner. 59, 359-377.

Fleischer, I., Agresti, D.G., Klingelhöfer, G. \& Morris, R.V. (2010). J. Geophys. Res. 115, E00F06.

Fraeman, A.A., Arvidson, R.E., Ehlmann, B.L., McGovern, J.A., Milliken, R.E., Murchie, S.L., Seelos, F.P. \& Seelos, K.D. (2012). In 43rd Lunar and Planetary Science Conf., abstract no. 2123.

Garvin, J.B., Sakimoto, S.E.H. \& Frawley, J.J. (2003). In Sixth Int. Conf. on Mars, abstract no. 3277.

Geissler, P.E., Johnson, J.R., Sullivan, R., Herkenhoff, K., Mittlefehldt, D., Fergason, R., Ming, D., Morris, R., Squyres, S., Soderblom, L. et al. (2008). J. Geophys. Res. 113, E12S31.

Gendrin, A. et al. (2005). Science 307, 1587-1591.

Glotch, T.D., Bandfield, J.L., Christensen, P.R., Calvin, W.M., McLennan, S.M., Clark, B.C., Rogers, A.D. \& Squyres, S.W. (2006). J. Geophys. Res. 111, E12S03.

Golombek, M.P. et al. (2003). J. Geophys. Res. 108(E12), 8072.

Golombek, M.P. et al. (2006). J. Geophys. Res. 111, E12S10.

Golombek, M., Robinson, K., McEwen, A., Bridges, N., Ivanov, B., Tornabene, L. \& Sullivan, R. (2010). J. Geophys. Res. 115, E00F08.

Golombek, M.P., Grant, J., Kipp, D., Vasavada, A., Kirk, R., Fergason, R., Bellutta, P., Calef, F., Larsen, K., Katayama, Y. et al. (2012). Space Sci. Rev., in press, doi:10.1007/s11214-012-9916-y.

Grant, J.A., Golombek, M.P., Grotzinger, J.P., Wilson, S.A., Watkins, M. M., Vasavada, A.R., Griffes, J.L. \& Parker, T.J. (2011). Planet. Space Sci. 59, 1114-1127.

Greeley, R. \& Guest, J.E. (1987). U.S. Geol. Surv. Misc. Invest. Map, I-1802-B.

Grotzinger, J.P. \& Milliken, R.E. (2012). In Sedimentary Geology of Mars, ed. Grotzinger, J.P. \& Milliken, R.E, pp. 1-48. SEPM Special Publication No. 102.

Grotzinger, J.P. et al. (2005). Earth Planet. Sci. Lett. 240, 11-72.

Grotzinger, J.P. et al. (2012). Space Sci. Rev., in press, doi:10.1007/s11214012-9892-2.

Hartmann, W.K. \& Berman, D.C. (2000). J. Geophys. Res. 105(E6), 15,011-15,025.

Hobbs, S.W., Paull, D.J. \& Bourke, M.C. (2010). Icarus 210, 102-115.

Irwin, R.P. III \& Watters, T.R. (2010). J. Geophys. Res. 115, E11006.

Irwin, R.P. III \& Zimbelman, J.R. (2012). J. Geophys. Res. 117, E07004.

Irwin, R.P. III, Watters, T.R., Howard, A.D. \& Zimbelman, J.R. (2004). J. Geophys. Res. 109, E09011.

Irwin, R.P. III, Howard, A.D., Craddock, R.A. \& Moore, J.M. (2005). J. Geophys. Res. 110, E12S15.

Jaeger, W.L. et al. (2010). Icarus 205, 230-243.

Jakosky, B.M. \& Carr, M.H. (1985). Nature 315, 559-561.

Kerber, L. \& Head, J.W. (2010). Icarus 206, 669-684.

Kerber, L., Head, J.W., Madeleine, J.-B., Forget, F. \& Wilson, L. (2011). Icarus 216, 212-220.

Kerber, L., Forget, F., Madeleine, J.B., Wordsworth, R., Head, J.W. \& Wilson, L. (2012). In 43rd Lunar and Planetary Science Conf., abstract no. 1295.

Kite, E.S., Halevy, I., Kahre, M.A., Wolff, M.J. \& Manga, M. (2012a). Submitted manuscript available at http://arxiv.org/abs/1205.6226.

Kite, E.S., Lewis, K.W. \& Lamb, M.P. (2012b). Submitted manuscript available at http://arxiv.org/abs/1205.6840. 
Le Deit, L., Hauber, E., Fueten, F., Pondrelli, M., Zegers, T., van Gasselt, S., Massé, M., Verpoorter, C. \& the ISSI ILD team (2011a). In 42nd Lunar and Planetary Science Conf., abstract no. 1857.

Le Deit, L., Hauber, E., Fueten, F., Pondrelli, M., Rossi, A., Mangold, N., van Gasselt, S., Massé, M. \& Jaumann, R. (2011b). In European Planetary Science Conf. - Division for Planetary Sciences Joint Meeting, abstract no. 966.

Le Deit, L., Hauber, E., Fueten, F., Mangold, N., Pondrelli, M., Rossi, A. \& Jaumann, R. (2012). In Third Int. Conf. on Early Mars, abstract no. 7045 .

Lewis, K.W. \& Aharonson, O. (2011). In AGU Fall Meeting 2011, abstract no. P33C-1772.

Lewis, K.W., Aharonson, O., Grotzinger, J.P., Squyres, S.W., Bell, J.F. III, Crumpler, L.S. \& Schmidt, M.E. (2008a). J. Geophys. Res. 113, E12S36.

Lewis, K.W., Aharonson, O., Grotzinger, J.P., Kirk, R.L., McEwen, A.S. \& Suer, T.-A. (2008b). Science 322, 1532-1535.

Lewis, K.W., Aharonson, O., Grotzinger, J.P., McEwen, A.S. \& Kirk, R.L. (2010). In 41st Lunar and Planetary Science Conf., abstract no. 2648.

Malin, M.C. \& Edgett, K.S. (2000). Science 290, 1927-1937.

Malin, M.C., Edgett, K.S., Cantor, B.C., Caplinger, M.A., Danielson, G.E., Jensen, E.H., Ravine, M.A., Sandoval, J.L. \& Supulver, K.D. (2010). Mars 5, 1-60.

Mandt, K.E., de Silva, S.L., Zimbelman, J.R. \& Crown, D.A. (2008). J. Geophys. Res. 113, E12011.

Manga, M., Patel, A., Dufek, J. \& Kite, E.S. (2012). Geophys. Res. Lett. 39, L01202.

Mangold, N., Gendrin, A., Gondet, B., LeMouelic, S., Quantin, C., Ansan, V., Bibring, J.-P., Langevin, Y., Masson, P. \& Neukum, G. (2008). Icarus 194, 519-543.

Mangold, N., Baratoux, D., Arnalds, O., Bardintzeff, J.-M., Platevoet, B., Grégoire, M. \& Pinet, P. (2011). Earth Planet. Sci. Lett. 310, 233-243.

Massé, M., Bourgeois, O., Le Mouélic, S., Verpoorter, C., Le Deit, L. \& Bibring, J.P. (2010). Icarus 209, 434-451.

McLennan, S.M. et al. (2005). Earth Planet. Sci. Lett. 240, 95-121.

MEPAG ND-SAG (2008). Astrobiology 8, 489-535.

Metz, J.M., Grotzinger, J.P., Rubin, D.M., Lewis, K.W., Squyres, S.W. \& Bell, J.F. III (2009). J. Sed. Res. 79, 247-264.

Milliken, R.E., Grotzinger, J.P. \& Thomson, B.J. (2010). Geophys. Res. Lett. 37, L04201.

Milliken, R.E., Bristow, T. \& Bish, D.L. (2011). In 42nd Lunar and Planetary Science Conf., abstract no. 2230.

Ming, D.W., Morris, R.V. \& Clark, B.C. (2008). In The Martian Surface: Composition, Mineralogy, and Physical Properties, ed. Bell, J., pp. 519-540. Cambridge University Press, Cambridge.

Montgomery, D.R., Bandfield, J.L. \& Becker, S.K. (2012). J. Geophys. Res. 117, E03005.

Mumma, M.J., Villanueva, G.L., Novak, R.E., Hewagama, T., Bonev, B.P., DiSanti, M.A., Mandell, A.M. \& Smith, M.D. (2009). Science 323, 1041-1045.

Murchie, S., Roach, L., Seelos, F., Milliken, R., Mustard, J., Arvidson, R., Wiseman, S., Lichtenberg, K., Andrews-Hanna, J., Bishop, J. et al. (2009a). J. Geophys. Res. 114, E00D05.

Murchie, S.L. et al. (2009b). J. Geophys. Res. 114, E00D06.

Nealson, K.H. (1997). J. Geophys. Res. 102(E10), 23,675-23,686.

Niles, P.B. \& Michalski, J. (2009). Nature Geosci. 2, 215-220.

Niles, P.B. \& Michalski, J. (2012). In 43rd Lunar and Planetary Science Conf., abstract no. 2575.

Okubo, C.H. \& McEwen, A.S. (2007). Science 315, 983-985.

Okubo, C.H., Schultz, R.A., Chan, M.A., Komatsu, G. \& HiRISE Team (2009). Geol. Soc. Am. Bull. 121, 474-482.

Paige, D.A. (1992). Nature 356, 43-45.

Pavlov, A.A., Vasilyev, G., Ostryakov, V.M., Pavlov, A.K. \& Mahaffy, P. (2012). Geophys. Res. Lett. 39, L13202.

Pelkey, S.M. \& Jakosky, B.M. (2002). Icarus 160, 228-257.

Pelkey, S.M., Jakosky, B.M. \& Christensen, P.R. (2004). Icarus 167, 244- 270.
Poulet, F. \& Carter, J. (2012). In 43rd Lunar and Planetary Science Conf., abstract no. 1397.

Poulet, F., Arvidson, R.E., Gomez, C., Morris, R.V., Bibring, J.-P., Langevin, Y., Gondet, B. \& Griffes, J. (2008). Icarus 195, 106-130.

Rathbun, J.A. \& Squyres, S.W. (2002). Icarus 157, 362-372.

Roach, L.H., Mustard, J.F., Murchie, S.L., Bibring, J.-P., Forget, F., Lewis, K.W., Aharonson, O., Vincendon, M. \& Bishop, J.L. (2009). J. Geophys. Res. 114, E00D02.

Rogers, A.D. \& Bandfield, J.L. (2009). Icarus 203, 437-453.

Rossi, A.P., Neukum, G., Pondrelli, M., van Gasselt, S., Zegers, T., Hauber, E., Chicarro, A. \& Foing, B. (2008). J. Geophys. Res. 113, E08016.

Ruff, S.W. \& Christensen, P.R. (2002). J. Geophys Res. 107(E12), 5127.

Russell, P.S., Head, J.W. \& Hecht, M.H. (2004). In 35th Lunar and Planetary Science Conf., abstract no. 2007.

Saganti, P.B., Cucinotta, F.A., Wilson, J.W., Simonsen, L.C. \& Zeitlin, C. (2004). Space Sci. Rev. 110, 143-156.

Schorghofer, N. (2007). Nature 449, 192-194.

Schultz, P.H. \& Lutz, A.B. (1988). Icarus 73, 91-141.

Schwenzer, S.P., Abramov, O., Allen, C.C., Bridges, J.C., Clifford, S.M., Filiberto, J., Kring, D.A., Lasue, J., McGovern, P.J., Newsom, H.E. et al. (2012). Planet. Space Sci. 70, 84-95.

Scott, D.H. \& Chapman, M.G. (1995). U.S. Geol. Surv. Misc. Invest. Map, I-2397.

Scott, D.H. \& Tanaka, K.L. (1982). J. Geophys. Res. 87(B2), 1179-1190.

Silvestro, S., Vaz, D.A., Rossi, A.P., Flahaut, J., Fenton, L.K., Ewing, R. \& Geissler, P.E. (2012). In 43rd Lunar and Planetary Science Conf., abstract no. 1804.

Space Studies Board (2011). Vision and Voyages for Planetary Science in the Decade 2013-2022. National Academies Press, Washington.

Squyres, S.W. (1989). Icarus 79, 229-288.

Squyres, S.W. et al. (2004a). Science 305, 794-799.

Squyres, S.W. et al. (2004b). Science 306, 1709-1714.

Squyres, S.W. et al. (2009). Science 324, 1058-1061.

Steele, A. et al. (2012). Science 337, 212-215.

Stockstill, K.R., Moersch, J.E., Ruff, S.W., Baldridge, A. \& Farmer, J. (2005). J. Geophys. Res. 110, E10004.

Stockstill, K.R., Moersch, J.E., McSween, H.Y. Jr., Piatek, J. \& Christensen, P.R. (2007). J. Geophys. Res. 112, E01001.

Stoker, C.R. \& Bullock, M.A. (1997). J. Geophys. Res. 102(E5), 10,88110,888 .

Strom, R.G., Croft, S.K. \& Barlow, N.G. (1992). In Mars, ed. Kieffer, H.H. et al., pp. 383-423. University of Arizona Press, Tucson.

Sullivan, R. et al. (2008). J. Geophys. Res. 113, E06S07.

Summons, R.E., Amend, J.P., Bish, D., Buick, R., Cody, G.D., Des Marais, D.J., Dromart, G., Eigenbrode, J.L., Knoll, A.H. \& Sumner, D.Y. (2011). Astrobiology 11, 157-181.

Sumner, D.Y. (2004). J. Geophys. Res. 109, E12007.

Sumner, D.Y. (2011). In Fifth MSL Landing Site Workshop, Monrovia, California, USA. http://marsoweb.nas.nasa.gov/landingsites/ $\mathrm{msl} /$ workshops/5th_workshop/talks/Tuesday_AM/Sumner_Gale_opt.pdf

Tanaka, K.L. (1986). J. Geophys. Res. 91(B13), E139-E158.

Tanaka, K.L. (2000). Icarus 144, 254-266.

ten Kate, I.L. (2010). Astrobiology 10, 589-603.

Thomson, B.J., Bridges, N.T., Milliken, R., Bell, J.F. III, Calvin, W.C. \& Weitz, C.M. (2008). In 39th Lunar and Planetary Science Conf., abstract no. 1456.

Thomson, B.J., Bridges, N.T., Milliken, R., Baldridge, A., Hook, S.J., Crowley, J.K., Marion, G.M., de Souza Filho, C.R., Brown, A.J. \& Weitz, C.M. (2011). Icarus 214, 413-432.

Tirsch, D., Jaumann, R., Pacifici, A. \& Poulet, F. (2011). J. Geophys. Res. 116, E03002.

Tosca, N.J. \& Knoll, A.H. (2009). Earth Planet. Sci. Lett. 286, 379-386.

Tosca, N.J., Knoll, A.H. \& McLennan, S.M. (2008a). Science 320, 1204-1207.

Tosca, N.J., Milliken, R.E. \& Michel, F.M. (2008b). In Martian Phyllosilicates: Recorders of Aqueous Processes, abstract no. 7030.

Werner, S.C. (2009). Icarus 201, 44-68. 
Wiseman, S.M., Arvidson, R.E., Morris, R.V., Poulet, F., AndrewsHanna, J.C., Bishop, J.L., Murchie, S.L., Seelos, F.P., Des Marais, D. \& Griffes, J.L. (2010). J. Geophys. Res. 115, E00D18.

Wray, J.J. \& Ehlmann, B.L. (2011). Planet. Space Sci. 59, 196-202.

Wray, J.J., Ehlmann, B.L., Squyres, S.W., Mustard, J.F. \& Kirk, R.L. (2008). Geophys. Res. Lett. 35, L12202.

Wray, J.J., NoeDobrea, E.Z., Arvidson, R.E., Wiseman, S.M., Squyres, S. W., McEwen, A.S., Mustard, J.F. \& Murchie, S.L. (2009). Geophys. Res. Lett. 36, L21201.
Wray, J.J., Squyres, S.W., Roach, L.H., Bishop, J.L., Mustard, J.F. \& NoeDobrea, E.Z. (2010). Icarus 209, 416-421.

Wray, J.J. et al. (2011). J. Geophys. Res. 116, E01001.

Zabrusky, K., Andrews-Hanna, J.C. \& Wiseman, S.M. (2012). Icarus 220, 311-330.

Zimbelman, J.R. (2010). In 41st Lunar and Planetary Science Conf., abstract no. 1157.

Zimbelman, J.R. \& Scheidt, S.P. (2012). Science 336, 1683. 